\title{
A Content Analysis of Colour-term Conceptual Metaphors in Modern Persian Poetry*
}

\author{
Mohammad Aliakbari (Ilam), Mohammad Bagher Shabani (Qazvin) and Fereshteh \\ Khosravian (Ilam)
}

\begin{abstract}
This study sought answers related to the distribution of colour terms in Persian poems and their metaphoric reflection in poets' beliefs, ideas, or values. In so doing, 137 Persian verses from two poetry books with colour terms in content were considered for the analysis. Four raters who studied literature of Persian scrutinized the verses for the evaluation of the colour metaphoric conceptualizations. To validate the raters' suggestions, a focus group of sixteen commented on the recommended connotations. Results indicated that colours are not similarly distributed in Persian poems, are used with different conceptualizations and stood for both positive and negative connotations. Therefore, since colours are part of the authors' and speakers' daily lives to express information, knowledge of metaphoric expressions is suggested to be an inseparable part of language classes.
\end{abstract}

\section{$1 \quad$ Introduction}

For many years, scholars have been examining how metaphorical expressions connect to their cognitive geneses (Lakoff/Johnson 1980a, 1980b; Gibbs 1994; Fauconnier/Turner 1998; Forceville 2002; Goddard 2004). In cognitive linguistics, conceptual metaphor refers to the understanding of an abstract concept, called the target domain, in terms of a concrete concept of which one can have direct sensory experience, namely the source domain. This underlying association between the two domains is held to be systematic in both language and thought (Babarczy/Bencze/Fekete/Simon 2010: 1). As one of the first researchers to discern the abundance of metaphors in common language use, Reddy (1979) points out that the container metaphor, like words or sentences, is only a metaphor, and communication can be conceptualized in other ways. Lakoff/Johnson (1980b: 5) consider that understanding and experiencing one kind of thing in terms of another is the essence of metaphor in language. Based on Conceptual Metaphor Theory, Lakoff/Johnson (1999) perceive metaphor as a

\footnotetext{
* The authors would like to thank Soodabeh Seidi, Masoomeh Nadi, and Marzieh Ertebat for their insightful comments. Sincere appreciations also go to Setareh Bavand Pour for providing useful information. As of the date of publication of this issue, Mohammad Aliakbari and Fereshteh Khosravian are affiliated with the Ilam University (Iran) and Mohammad Bagher Shabani is affiliated with the Imam Khomeini International University of Qazvin (Iran).
} 
conceptual mapping of concrete knowledge onto abstract knowledge. Thus, the metaphor system is central to one's understanding of experience and to the way $\mathrm{s} / \mathrm{he}$ acts on that understanding.

Metaphor appears to be anywhere, in riddles, folk expressions, proverbs, clichés, literal words, slang, contemporary humor (Bartel 1983: 42) and particularly in poems. Some metaphorical concepts seem to be universal, others are widespread, and some seem to be culture-specific (Lakoff 1993: 245). Colour terms are literally and metaphorically used in different language genres, and often reflect cultural identities of the language user (Li/McGregor 2009). Since literary language shares much with ordinary language, and artistic usage with everyday usage, discoveries about one usually bear on the other (Lakoff 1987, cited in Yu 2003).

Lakoff/Turner (1989) define poetic language as something that is beyond ordinary language and also it is essentially different, special, and higher, with extraordinary tools and techniques like metaphor and metonymy, instruments beyond the reach of someone who just talks. Bearing these entire in mind, the need to know how metaphorical expressions in everyday language can give people insight into the metaphorical nature of the concepts organizing the everyday activities (Lakoff/Johnson 1980a) makes metaphorical concepts in poetry worth studying. In this regard, to see how a poet differently applies various kinds of conceptual metaphor, the researchers made an attempt to discern a good source for modern poetry to extract the most relevant poems, those including colour terms, to be scrutinized for their frequent metaphorical conceptualizations.

\section{Review of Literature}

Studies conducted by linguistic anthropologists identified similarities as well as differences in perceptions of colours across cultures (Hupka/Zaleski/Otto/Reidl/Tarabrina 1997). Researchers have also examined how pictorial and colour interpretations differ among individuals and across cultures (Leonard/Karens/Schneider 1988; Leonard/Hill/Karens 1989; Chapanis 1994; Wogalter/Fredrick/Herrera/Magurno 1997; Cienki 1999; Smith-Jackson/Wogalter 2000).

Adams/Osgood (1973) accumulated colour data from 23 cultures conducting a differential study of affective meanings to show cross-cultural similarities in feelings about colours. The results revealed that the concept of red was affectively quite salient. Black and grey were bad, and white, blue, and green were good. Yellow, white, and grey were weak; red and black were strong. Black and grey were passive; red was active. The colour component brightness, as determined by comparing data on white, grey, and black, was strongly associated with positive evaluation and a negative potency. Due to the fact that there were very few exceptions in their data or the literature, they argued that there were strong universal trends in the attribution of affect in the colour domain.

More than two decades later, Hupka et al. (1997) investigated word associations or verbal synesthesia between concepts of colour and emotions in Germany, Mexico, Poland, Russia, and the United States. With emotion words as the between-subjects variable, 661 undergraduates indicated on 6-point scales to what extent anger, envy, fear, and jealousy reminded them of 12 terms of colour. In all nations, the colours of anger were black and red, fear was black, and jealousy was red. Cross-cultural differences were: Poles connected anger, envy, and jealousy with purple as well; Germans associated envy and jealousy with yellow; and Americans 
A Content Analysis of Colour-term Conceptual Metaphors in Modern Persian Poetry

associated envy with black, green, and red, but for the Russians it was black, purple, and yellow. The findings suggested that cross-modal associations originate in universal human experiences and in culture-specific variables, such as language, mythology, and literature.

A few years later, Smith-Jackson/Wogalter (2000) examined colour and symbol hazard ratings among monolingual participants whose primary language was English. Participants rated perceived hazards of ten American National Standards Institute (ANSI) safety colours and six symbols. Red, followed by yellow, black, and orange, were given the highest hazard ratings. The skull, prohibition, and the shock symbols produced the top three hazard ratings. The results were compared to a previous study by Wogalter/Frederick/Herrera/Magurno (1997) who examined hazard ratings among participants whose primary language was Spanish. Comparisons supported general similarities between certain colour and symbol hazard ratings among Spanish and English language users.

In another study, Bottomley/Doyle (2006) explored the role of colour in building brand meaning with two experiments. Without prior conditioning, they demonstrated how an appropriately chosen colour for a brand name (logo) could bring inherent and immediate value to a brand. In the first experiment, they explored the notion of congruity, showing that it was more appropriate for functional products to be presented in functional colours, and sensorysocial products in sensory-social colours. In the second experiment, they examined the effect of red and blue on brands of products that could be classified as both functional and sensorysocial, and the ability of colour to enhance a brand's desired image. When people knew how brands were attempting to position themselves, they considered colours congruent with those positions to be more appropriate.

Phillip (2006) examined the use of colour-word metaphors in English and Italian through the data took out of general reference corpora and traditional reference works. She mostly focused on the ways in which colour words took on connotative meanings, how the meanings were fixed linguistically, and similarities and differences across the pertinent languages. Parts of the findings are presented in the discussion section.

In another attempt, Koller (2008) sought answers related to the functions of the colour pink as a marker of gender and sexuality in cultural models and the multimodal texts they informed. To this end, tendencies suggested by a pilot survey on colour associations were traced in a number of visual texts such as leaflets, advertisements, websites, and magazines, where pink attracts female readers' attention and indexes both sexuality and sexual identity. Both informants' associations and the multimodal text analysis showed evidence of an emergent schema that related pink to postfeminist femininity. It was seen as complementing and extending conventional and counter-cultural associations of pink with stereotypically feminine characteristics or gayness, respectively. At the end, she suggested an approach for the colour combining social semiotics with cognitive semantics and also she regarded pink as a gender and sexuality marker in visual communication.

He (2009) made an attempt to study colour at different cultural backgrounds shown in different cultural connotation. He believes that there are words and phrases about colour in Chinese and English which play a crucial role in intercultural communication of modern world. Due to various cultural backgrounds, English colour words connotation has great dissimilarities. He concluded that the meaning of the colour in Chinese and Western cultures has frequently diverse 
specifications, and that colour may become a colour taboo or a colour worship based on the relevant connotations.

Gieron-Czepczor (2010) conducted a study concerning the polysemies of two equivalent basic colour terms; English red and Polish czerwony. The analysis included the core and peripheral readings revealed through the investigation of large samples of corpus citations retrieved from the British National Corpus and the Corpus of Polish. Drawing on the prototype theory, cognitive mechanisms of meaning extensions, conceptual metonymies and metaphors, and corpus data, the research compared and contrasted the resulting radial networks and entrenchment of respective readings for the two colour terms as semantic categories. The outcome clearly recommended that blood and fire influence the conceptualizations underlying the usage of red in both languages.

Eslami Rasekh/Ghafel (2011) investigated the extent to which basic colours connotations, are employed in metaphors structure in English and Persian. English instances were extracted from The Oxford Dictionary of Idioms (Siefring 2005) and The Oxford Dictionary of Proverbs (Speake 2008) and some other dictionaries. They collected Persian instances from some Persian dictionaries. The results demonstrated that most of the expressions were culture-bound, though the connotation of colours in the structure of metaphorical expressions were somewhat overlapping.

Al-Adaileh (2012) examined the X-phemistic uses of Arabic colour terms with especial reference to Jordanian Arabic. Adopting colour-based metaphors, the study explored the figurative uses of black, white, yellow, red, green and blue; the most common colours that are used figuratively. The connotations of Arabic colour terms were judged on the basis of whether the phrases in which colour terms occur are orthophemistic, euphemistic or dysphemistic. Building on the pertinent colours, he concluded that colours had many orthophemistic connotations, and their dysphemistic connotations were more common than euphemistic connotations. Besides, he found that the uses of black, yellow, red and blue were predominantly dysphemistic. In contrast, white mostly had positive connotations and green was found to be associated with both euphemistic and dysphemistic connotations.

Aliakbari/Khosravian (2013) investigated the distribution of colour terms and their metaphoric reflection in the users' beliefs, ideas or values in Persian proverbs based on three Iranian proverb books. Through examining as many as 4710 proverbs in the pertinent books, they selected and analyzed a corpus of 56 Persian proverbs with colour terms in content. The findings made it clear that colours were not equally distributed in Persian proverbs and that they stood for both positive and negative connotations. Since metaphoric expressions are an undividable feature of spoken and written language, they came to the conclusion that language users need to attain adequate awareness of these expressions in different domains.

Understanding from the literature, most of the studies accomplished on conceptual metaphor of colours have either focused on some particular colours in western languages or have been done in the context of casual or written discourse. Due to scarcity of studies accomplished on the use, frequency and distribution of conceptual metaphor of colours across languages in general and Persian in particular, the present study investigated the conceptual metaphor of colours in poems to figure out the frequent colours and the common conceptualizations those colours signify in Persian. 


\section{$3 \quad$ Focus of the study}

Colours are among the words to which attention needs to be drawn. Conceptual knowledge of this sort is less easy to pin down than one might like to think. Besides, the use of an appropriate colour may not necessarily result in the use of an appropriate or acceptable expression. To account for the probable misunderstanding and to see how different or similar colours are in different cultures, this study tried to present a vivid picture of the conceptual metaphors of colours in the case of poems to seek the conspicuity of Persian literature for the readers.

With regard to what has already been stated and based on the objectives of the research, the following research questions were sought to answer:

1. How balanced is the use of colour terms in modern Persian poetry?

2. To what extent are the poet's beliefs, ideas, or values reflected in the use of colour metaphors?

3. To what extent the colour terms used in metaphoric poems express positive or negative connotations?

\section{$4 \quad$ Method}

This paper comprised an exploratory study of the conceptual metaphor of colours in Persian poems. It intended to analyze the poems in terms of the colours, to examine the distribution of colours among Persian poems by a contemporary Persian poet, to investigate the poet's conceptualizations associated with colours, and to detect whether they signify positive or negative impression to the language users. Additionally, as a supporting research method, focus groups were employed to provide internal validation for the findings. Focus groups, sometimes referred to as group interviews, are conducted conversations in which a researcher, or research team, encounters with a group of equally situated people for purposes of revealing information about a topic (Tewksbury 2009: 47).

\subsection{The material of the study}

Consulting some literature professors, Sohrab Sepehri's (1928-1980) works were adopted for the study and analysis. Integrating visual images taken from painting with eastern mysticism, Sepehri, a contemporary poet whose major interest was metaphor, produced a kind of unique and original poetry. Since Sepehri's style was symbolic, close to the purpose of the study, and he was both a mystical painter and a poet, it was assumed that his works could display a better and somehow different understanding of colours compared to other symbolic poets in his era. Moreover, he frequently employed colours through different concepts to demonstrate the mystical style in his paintings. Among his masterpieces, two books, namely The secret of red flower (Sepehri 2005) and Eight books (Sepehri 1996) were selected. Through the investigation of the poems, 137 verses including colour terms or the connoting words of colours, the quantity of which allowed the researchers for valid generalization, were selected. English translation of the selected Persian verses is presented in the appendix. A part of the translation was extracted from Sepehri's books, translated by Salami/Zahedi (Sepehri 2007) and Zahedi (Sepehri 2008), shown by ${ }^{\circledR}$, and the rest were translated by the researchers. It is worth noting that colour terms 
in some of the English translated version of the poems do not seem metaphoric though they unquestionably are in the Persian version.

\subsection{Procedure}

It took about six months to conduct the research and to collect the data. To manage the data, some verses (sentences) including two or more colour terms were written twice to avoid probable ambiguity. They were also numbered from 1 to 137 for easier analysis (see appendix). To evaluate the accuracy of the conceptualizations of colours within the poems, three Master students majored in Persian literature were asked to examine the selected verses providing us with their comments. In those colour terms the raters were in doubt regarding a concept, another rater, who was also a Persian Literature Master student, checked the possibility of the connotation. They also provided suggestions on positive/negative attributes of the included colours in the selected poems. As mentioned earlier, focus group was consulted to validate the raters' suggestions on the metaphoric conceptualizations of the relevant colours. In so doing, two focus groups, involving six sessions, were conducted. One group comprised six people and the other ten, ranging in age from 16 to 27 and 18 to 32 for the first and second groups respectively. Each session lasted about ninety minutes and organized by the researchers, who presented the Persian verses on the monitor, about 45 verses for each session, and asked the subjects to comment on the prepared connotations by the raters as they had some ready handouts. The subjects in focus groups were allowed to interact with minimum interruption.

\section{$5 \quad$ Result}

For the number of colours in content and for the balance of the different colour terms frequency, the materials were analyzed quantitatively (illustrated in Table 1).

\begin{tabular}{lccccccccccc}
\hline Colours & Green & Black & Blue & White & Red & Violet & Golden & Grey & Yellow & Orange & Total \\
\hline Frequency & 36 & 35 & 19 & 17 & 10 & 7 & 6 & 4 & 2 & 1 & $\mathbf{1 3 7}$ \\
Percent & 26.27 & 25.55 & 13.87 & 12.41 & 7.30 & 5.11 & 4.38 & 2.92 & 1.46 & 0.73 & $\mathbf{1 0 0}$ \\
\hline
\end{tabular}

Table 1: Frequency of colours in Sepehri's poems

Subsequently, the most frequent metaphoric conceptualizations associated with the pertinent colours, besides their positive and negative attributes were determined. The frequency of colours, their conceptual metaphors, the poem numbers, and their positive/negative attributes are illustrated in Table 2.

\begin{tabular}{|c|c|c|c|c|}
\hline & $\begin{array}{c}\text { Frequency } \\
\text { of poems } \\
\text { with } \\
\text { colour- } \\
\text { term } \\
\text { metaphors }\end{array}$ & Possible conceptualizations & Poem number & $\begin{array}{c}\text { Attribute } \\
\text { (Positive/Negative) }\end{array}$ \\
\hline & & - $\quad$ peace & $1,2,8,15,18,24,30,36$ & $\mathbf{P}$ \\
\hline & & - cognition & $3,12,17,27,35$ & $\mathbf{P}$ \\
\hline & & - $\quad$ vitality & $4,11,23,25,26$ & $\mathbf{P}$ \\
\hline & & - fertility & $5,13,28,32,33,34$ & $\mathbf{P}$ \\
\hline & & - the passion of guidance & 6 & $\mathbf{P}$ \\
\hline & & - $\quad$ essence greatness & 7,9 & $\mathbf{P}$ \\
\hline 1 & $\begin{array}{c}\text { Green } \\
(\mathbf{3 6})\end{array}$ & - $\quad$ spirit liberation & 10 & $\mathbf{P}$ \\
\hline
\end{tabular}


Mohammad Aliakbari, Mohammad Bagher Shabani and Fereshteh Khosravian:

A Content Analysis of Colour-term Conceptual Metaphors in Modern Persian Poetry

\begin{tabular}{|c|c|c|c|c|}
\hline & & $\begin{array}{ll}\text { - } & \text { immaculacy } \\
\text { - } & \text { ornament of the world } \\
\text { - } & \text { affection } \\
\text { - } & \text { goodness } \\
\text { - } & \text { stability in friendship } \\
\text { - } & \text { deceptive world }\end{array}$ & $\begin{array}{l}14 \\
16,19 \\
20,24 \\
21,31 \\
22 \\
29\end{array}$ & $\begin{array}{l}\mathbf{P} \\
\mathbf{P} \\
\mathbf{P} \\
\mathbf{P} \\
\mathbf{P} \\
\mathbf{N}\end{array}$ \\
\hline 2 & Black (35) & $\begin{array}{ll}\text { - } & \text { perfection } \\
\text { - } & \text { distance } \\
\text { - } & \text { sorrow } \\
\text { - } & \text { captive } \\
\text { - } & \text { (pure) aberrance } \\
\text { - } & \text { death } \\
\text { - } & \text { disappointment } \\
\text { - } & \text { deception } \\
\text { - } & \text { initial existence } \\
\text { - } & \text { agony } \\
\text { - } & \text { wild world } \\
\text { - } & \text { stability } \\
\text { - Savior }\end{array}$ & $\begin{array}{l}37,53 \\
38,42,43 \\
39 \\
40,50 \\
41,48,52,62,63 \\
47 \\
44,45,55,57,58,67,70 \\
46,51,54 \\
49 \\
56 \\
59 \\
60,69 \\
61,64,68,71 \\
65,66\end{array}$ & $\begin{array}{l}\mathbf{P} \\
\mathbf{N} \\
\mathbf{N} \\
\mathbf{N} \\
\mathbf{N} \\
\mathbf{N} \\
\mathbf{N} \\
\mathbf{N} \\
\mathbf{P} \\
\mathbf{N} \\
\mathbf{P} \\
\mathbf{N} \\
\mathbf{P} \\
\mathbf{P}\end{array}$ \\
\hline 3 & Blue (19) & $\begin{array}{ll} & \text { sophistry (deception) } \\
\text { - } & \text { verity } \\
\text { - } & \text { Immaculacy } \\
\text { - } & \text { Disappointment } \\
\text { - } & \text { Stability } \\
\text { - } & \text { sensual and mundane } \\
& \text { belongings } \\
\end{array}$ & $\begin{array}{l}72 \\
73,78,90 \\
74,75,87 \\
76,77,79,81,84,85,88,89 \\
80 \\
82,83 \\
86\end{array}$ & $\begin{array}{l}\mathbf{N} \\
\mathbf{P} \\
\mathbf{P} \\
\mathbf{P} \\
\mathbf{N} \\
\mathbf{P} \\
\mathbf{N}\end{array}$ \\
\hline 4 & White (17) & $\begin{array}{ll}\text { - } & \text { immaculacy } \\
\text { - } & \text { beauty } \\
\text { - } & \text { mercy } \\
\text { - } & \text { independence } \\
\text { - } & \text { transitory } \\
\text { - } & \text { peace } \\
\end{array}$ & $\begin{array}{l}91,93,94,95,97,99,100, \\
103,105,106,107 \\
92,102 \\
96 \\
98 \\
101 \\
104 \\
\end{array}$ & $\begin{array}{l}\mathbf{P} \\
\mathbf{P} \\
\mathbf{P} \\
\mathbf{N} \\
\mathbf{P}\end{array}$ \\
\hline 5 & Red (10) & $\begin{array}{ll}\text { - } & \text { passion } \\
\text { - } & \text { enthusiasm } \\
\text { - } & \text { ontology } \\
\end{array}$ & $\begin{array}{l}108,109,110,115,117 \\
111,113,114,116 \\
112\end{array}$ & $\begin{array}{l}\mathbf{P} \\
\mathbf{P} \\
\mathbf{P}\end{array}$ \\
\hline 6 & Violet (7) & $\begin{array}{ll}\text { - } & \text { disappointment } \\
\text { - } & \text { grief } \\
\text { - } & \text { projection } \\
\end{array}$ & $\begin{array}{l}118,119,122,123 \\
120,121 \\
124\end{array}$ & $\begin{array}{l}\mathbf{N} \\
\mathbf{N} \\
\mathbf{N}\end{array}$ \\
\hline 7 & Golden (6) & $\begin{array}{ll}\text { - } & \text { shandy } \\
\text { - } & \text { pure and shiny } \\
\text { - } & \text { glorious past } \\
\text { - } & \text { precious }\end{array}$ & $\begin{array}{l}125,126,128 \\
127 \\
129 \\
130\end{array}$ & $\begin{array}{l}\mathbf{P} \\
\mathbf{P} \\
\mathbf{P} \\
\mathbf{P}\end{array}$ \\
\hline 8 & Grey (4) & $\begin{array}{ll}\text { - } & \text { solitude } \\
\text { - } & \text { injustice }\end{array}$ & $\begin{array}{l}131,132,133 \\
134\end{array}$ & $\begin{array}{l}\mathbf{N} \\
\mathbf{N}\end{array}$ \\
\hline 9 & Yellow (2) & $\begin{array}{ll}\text { - } & \text { vitality } \\
\text { - } & \text { disappointment }\end{array}$ & $\begin{array}{l}135 \\
136\end{array}$ & $\begin{array}{l}\mathbf{P} \\
\mathbf{N}\end{array}$ \\
\hline 10 & $\begin{array}{c}\text { Orange } \\
\text { (1) }\end{array}$ & - hope & 137 & $\mathbf{P}$ \\
\hline
\end{tabular}

Table 2: Colours frequent metaphoric conceptualizations (Note. P: Positive, N: Negative)

Different colours as well as their corresponding conceptual metaphors through the number of relating examples are demonstrated in the table. A thorough explanation on their metaphoric expressions is presented in discussion section. 


\section{Discussion}

An indispensable element of human life, including language, thought and action is metaphorical language (Lakoff/Johnson 1980b). As aforementioned, metaphor has a crucial place in people's common language use and thinking. Humans' conceptual system is framed according to their experiences of interacting with people and things surrounding them. In this spirit, colour functions an essential part in conventional metaphoric expressions in people's lives and daily communication. That is, colour terms, as a sub-category of metaphors, are broadly employed literally and metaphorically in different languages and reflect cultural identities of language users. Accordingly, the main concerns of the present study were investigating the distribution of colour terms in Persian poems, their conceptual metaphor, and their positive/negative attribute in poet's beliefs, ideas or values.

Analyzing the data, demonstrated in Tables 1 and 2, in Sepehri's poetry, green with frequency of 36 is the most frequent colour. Concerning the second and third research questions, green is primarily associated with peace represented in examples $1,2,8,15,18,24,30$ and 36. Fertility (examples 5, 13, 28, 32, 33 and 34) is the second frequent concept found for this colour. Cognition and vitality are two other implied meanings respectively connected with green in poems 3, 12, 17, 27, 35 and 4, 11, 23, 25, 26. Essence greatness ( 7 and 9), world ornament (16 and 19), affection (20 and 24), and goodness (21 and 31) are the other conceptualizations of green discovered through the same frequency, 2. For other connotations of green such as the passion of guidance, spirit liberation, immaculacy and stability in friendship; poems number 6, 10, 14 and 22 are suggested correspondingly. And finally, deceptive world, seen in example 29, is the only negative concept associated with this colour. As a result, it can be claimed that green is mostly a positive colour with just one negative conceptualization in the pertinent poems. However, in English, by Shakespeare's time, green is often associated with jealousy and envy (Phillip 2006, 2011). The metaphorical expressions green with envy (Green is associated with envy, so jealous suitors used green jade as a potion) and 'green-eyed' (the green-eyed monster in Othello) show the association of green with jealousy and envy clearly (ibid.). Eslami Rasekh/Ghafel (2011) asserts that green, in Persian, is the colour of vegetarian and nature and it symbolizes the young, freshness and growth and is associated with initial stages of maturation. Moreover, it is taken for safety, hope, peace and environment protection in other contexts (Li/McGregor 2009). Green also exhibits the idea of inexperience, an immature state. So it can be used ranging from unripe corn to person (Phillip 2006, 2011).

Black, the second frequent colour of the selected poems, has both negative and positive connotations. It typically exhibits disappointment in examples 44, 45, 55, 57, 58, 67 and 70. It also symbolizes absolute aberrance in the poems 41, 48, 52, 62 and 63. Distance (examples 38, 42 and 43) and deception (examples 46, 51 and 54) are two other connotations of this colour with the same frequency. Other negative concepts are captivity; examples 40 and 50, and wild world; examples 60 and 69. Still other negative conceptualizations like sorrow (example 39), death (example 47), and agony (example 56) are associated with black in Sepehri's poems. Regarding the positive concepts of black, five attributes (frequency: 10) are extracted from the poems including this colour; stability (examples 61, 64, 68 and 71), perfection (examples 37 and 53), savior (examples 65 and 66), initial existence (example 49), and conscience ascension (example 59). Having all these in mind, black can be considered as a both negative and positive 
A Content Analysis of Colour-term Conceptual Metaphors in Modern Persian Poetry

colour; though, it is inclined to negativeness, seen in the Table 2. In western culture, the black colour is the sign of darkness. In Bible, black stands for the devil, pain and misfortune (He 2009). Black was associated even in Elizabethan times with dirty, sinister and wicked qualities, as opposed to white which stood for beauty, virtue and goodness (Benczes 2007).

As observed in the taxonomy, the third frequent colour is blue, presented in 19 examples, some of which including 76, 77, 79, 81, 84, 85, 88 and 89 are associated with peace. It also represents verity (examples 73, 78 and 90), immaculacy (examples 74, 75 and 87), and stability (examples 82 and 83). Considering these concepts as positive, blue has negative attribute as well, such as; sophistry or deception (example 72), disappointment (example 80), and sensual and mundane belongings (example 86). In Italian, there are two basic terms for blue; blu and azzurro, dark blue and light blue respectively. The sky is light blue and the sea is dark blue, and as a result, the metaphorical expressions relating to the sky are connected with light blue while those correlating with the sea are associated with dark blue (Phillip 2006, 2011). However, English has only one basic term for blue and the different symbolic characteristics of the colour(s) associated with the sea and the sky are all considered for that one. Itten (1961: 136) suggests that in Italian, blue in its darker shades, "falls into superstition, fear, grief and perdition".

The fourth mostly observed colour in the poems is white. It primarily symbolizes immaculacy observing in examples 91, 93, 94, 95, 97, 99, 100, 103, 105, 106 and 107. Beauty (examples 92 and 102), mercy (example 96), independence (example 98) and peace (example 104) are other implications of this colour all of which regarded as its positive attributes. Transitory (example 101 ) is the only concept causes white to seem slightly negative. According to Ferdowsi's great epic book, Shaahnameh, in ancient Iran, especially in Persian mythology, white is the symbol of superiority, spirituality and virtue (Eslami Rasekh/Ghafel 2011). Additionally, knowledge ability of elderly people and their life experiences are referred to white in Persian. White, symbolizing mourning or death in East Asia (Paul/Okan 2010: 950), is viewed positively in Arabic as it is mostly associated with purity and innocent, harmless, and evil-free issues. In the cultural context of Jordan, white may be viewed positively, in that white normally stands for innocence, purity and peace (Al-Adaileh 2012). Adams/Osgood (1973) found that young adult subjects rated white more positively than black in all of the 23 language-culture groups studied in Europe, Asia and the America. Jacobs/Keown/Worthley/Ghymn (1991) state that white is associated with cleanliness, though cross-cultural differences are noted to exist. They further note that white has the largest number of positive responses.

Red, the colour of passion and love in Persian literature, mostly signifies passion in the examples 108, 109, 110, 115 and 117. It also connotes enthusiasm (examples 111, 113, 114 and 116) and ontology (example 112). Therefore, it can be considered as an absolute positive colour. In American history, red is not a very good word; it is associated with "fire" and "blood", and symbolizes cruelty, war, violence and revolution (He 2009). As Itten observed (1961: 34, cited in Phillip 2006), red is the colour of revolution because of its links with political favor and spilled blood. Red has traditionally been regarded as a symbol of guilt, sin and anger, often as connected with blood, sex and lust (Oehler/Day 1883, 1978: 320 cited in Gieroń-Czepczor 2010).

Violet or purple, as the sixth colour of the material, was presented in 7 examples. Observing in examples 118, 119, 122 and 123; disappointment is the most frequent conceptualization 
associated with this colour. Subsequently, grief, found in examples 120 and 121, and projection in example 124 were the other conceptualizations. It, thus, can be considered as a thorough negative colour. In English, this colour is imbued with the notion of sumptuousness, though often taken to the extreme and thus tinged with negative connotations: purple prose, and the related expressions purple passage and purple patch, all of which refer to excessively ornate passages in literary prose (Phillip 2006, 2011). To Phillip, the Church's adoption of purple at Easter time is probably responsible for this colour's symbolic connection with strong emotion, passion, whether romantic or otherwise: viola is considered unlucky in Italy because of its association with the passion and death, though this association is not present in Anglophone cultures, nor can it be found in metaphorical idioms or other conventional linguistic expressions in Italian.

Based on the examples 125,126 , and 128 , gold or golden mostly signifies shandy. It connotes pure and shiny (example 127), glorious past (example 129), and preciousness (example 130); as a result, it is considered a positive colour. In English, gold represents what is precious and valuable, and also denotes majesty, joy, and celebration (Bratcher 2012). In addition, its brightness metallic gold represents the presence of God (ibid.).

As observed in the taxonomy, the eighth colour is grey. In examples 131, 132 and 133, grey is primarily associated with solitude. Injustice is another association (example 134). Hence, it can be considered as another negative colour. To Phillip (2006: 77), grey can both convey the negativity of black as well as the positive values related with white, functioning as a mid-way point between extremes, to moderate colours down to a monotonous, nondescript hue. She (ibid.) also recommends that the association of grey with obfuscation and uncertainty is reflected in both English and Italian.

The other colour with the frequency of two is yellow. This colour is typically associated with vitality and disappointment, seen in examples 135 and 136 correspondingly. Established upon the analysis of the poems found in the abovementioned books, yellow can be regarded as a colour of both positivity and negativity. Metaphorical expressions that are constructed around yellow have associative meanings to illness, stagnation and death (Eslami Rasekh/Ghafel 2011). It is the colour of autumn, which reminds people falling leaves of trees and stagnate vision. Certain light colours possess a negative cultural connotation, if used with reference to facial colour, e.g., yellow colour. Eslami Rasekh/Ghafel (2011) continue that yellow cannot signify a positive emotion in Persian, even though it is a light colour. Kiato/Kiato (1986) claim that yellow does not customarily suggest or imply cowardice for Asians as it does for Americans.

The last colour of the taxonomy is orange (frequency: 1). As observed in the last example (number 137), it signifies hope which in turn makes it a positive colour. The only symbolism usually associated with orange derives from its connection with the colours of fire and light, red and yellow, (Phillip 2006: 88). She further states that no linguistic metaphor concerning orange has been recognized in either Italian or English.

It is noteworthy that the participants in both focus groups confirmed the raters' proposed conceptual metaphors for the relevant colours recently discussed. 
The current study was an attempt to identify the balance of colour terms in a relatively representative modern Persian poetry, examination of the extent of the poet's beliefs, ideas, or values reflected in the use of colour metaphors as well as the positive or negative connotations of colour terms used in metaphoric poems were other motives of the study. On the basis of the results, it is right to maintain that the distribution of colour terms among Persian poems is varied. As can be observed in Table 1, 26.27 percent of the total colour term conceptual metaphors in the given poetic material belongs to green and 25.55 percent to black, 13.87 percent to blue, 12.41 percent to white, 7.30 percent to red, 5.11 percent to violet, 4.38 percent to golden, 2.92 percent to grey, 1.46 percent to yellow, and 0.73 to orange.

Moreover, the poet's opinions, thoughts and values are scrupulously reflected in his use of colour metaphors. The analysis also showed that the conceptualizations associated with the present colour terms, (positive, negative or both) were verified to be different by the poet. Therefore, red, golden, and orange are often considered as positive; violet and grey as negative; and green, black, blue, white and yellow as both positive and negative. Concerning the last cluster; green, black, blue, white and yellow; it should be mentioned that based on their conceptualizations (Table 2), green and white can mostly be considered as positive colours and black as a negative one. Comparing the present findings with Aliakbari/Khosravian's (2013), they (ibid.) concluded that green and red are positive; black, yellow and violet are negative; and white is both positive and negative in metaphoric use. Then, it can be decided that the conceptualizations of the colours for both poetry and proverbs are somewhat identical.

Although the study conducted in the present article was a preliminary piece of research, its findings may inspire pedagogical implications. In studies of metaphor, one important concern is the role that metaphor plays in learning and teaching. Awareness of such devices and their organization and use can help, along with other things, those involved in language pedagogy. There is evidence for the link between conceptual metaphor and cultural models that came from Cienki (1999), who showed that conceptual metaphors and cultural models are interrelated, whereby cultural models seem to exert pressure on the flow of conceptual metaphors. In this regard, the results can function accurately as an instrument for efficiently preventing the miscommunication and misinterpretation while communicating people from different cultures and reading different types of texts in Persian.

The results of the present research can be compared with the studies conducted in other languages to evaluate the degree of similarities and differences among different languages and cultures. Furthermore, the difference between the present results and the findings of other studies in the literature may necessitate teaching metaphoric meanings and cultural differences to Persian as well as English learners. It means that metaphoric texts should be included in the curriculum of the learners by curriculum developers. The findings can also specify the importance of metaphor in general and colour metaphor in particular in cross cultural communications since lack of familiarity and attention may lead to speakers' and listeners' misunderstanding during conversations.

A limitation worth acknowledging is that this study concentrated only in Persian language and culture, therefore, it is suggested that the study be replicated in more linguistic and cultural backgrounds to check if the same findings are attained. Moreover, as a suggestion for further 
research, , it is recommended to seek the relationship between the colours of the national flags and people's favorite colours of the related country since every country's flag is made of different colours.

\section{References}

Adams, Francis M./Osgood, Charles E. (1973): "A cross-cultural study of the affective meanings of colour". Cross-Cultural Psychology 4: 135-156.

Al-Adaileh, Bilal A. (2012): "The connotations of Arabic colour terms". Linguistica online: 118. http://www.phil.muni.cz/linguistica/art/al-adaileh/ada-001.pdf, accessed May 12, 2015.

Aliakbari, Mohammad/Khosravian, Fereshteh (2013): "A corpus analysis of colour-term conceptual metaphors in Persian Proverbs". Procedia Social and Behavioral Sciences 70: $11-17$.

Babarczy, Anna/Bencze M., Ildiko/Fekete, Istvan/Simon, Eszter (2010): "The automatic identification of conceptual metaphors in Hungarian texts: A corpus-based analysis". Proceedings of LREC 2010 Workshop on Methods for the Automatic Acquisition of Language Resources, Malta: 30-37.

Bartel, Ronald (1983): Metaphors and Symbols: Forays into Language. Urbana, IL: National Council of Teachers of English.

Benczes, Réka. (2007): North American Slavery: A Cognitive Linguist's Perspective. http://www.das.elte.hu/content/faculty/benczes/benczes_frank_t.pdf, accessed February 23, 2014.

Bottomley, Paul A./Doyle, John R. (2006): "The interactive effects of colours and products on perceptions of brand logo appropriateness". Marketing Theory 6/1: 63-83.

Bratcher, Dennis (2012): The meaning of church colours. http://www.crivoice.org/symbols/coloursmeaning.html, accessed February 24, 2014.

Chapanis, Alphonse (1994): "Hazards associated with three signal words and four colours on warning signs". Ergonomics 37: 265-275.

Cienki, Alan (1999): "Metaphors and cultural models as profiles and bases". In: Gibbs, Raymond W./Steen, Gerard J. (eds.) (1999): Metaphor in Cognitive Linguistics. Amsterdam: John Benjamins.

Eslami Rasekh, Abbas/Ghafel, Banafsheh (2011): "Basic Colours and Their Metaphorical Expressions in English and Persian: Lakoff's Conceptual Metaphor Theory in Focus". 1st International Conference on Foreign Language Teaching and Applied Linguistics, May 57, 2011 Sarajevo: 211-224.

Fauconnier, Gilles/Turner, Mark (1998): "Conceptual integration networks". Cognitive Science 22/2: 133-187.

Forceville, Charles (2002): "The identification of target and source in pictorial metaphors". Pragmatics 34: 1-14.

Gibbs, Raymond W. Jr. (1994): The Poetics of Mind. Cambridge: Cambridge University Press.

Gieroń-Czepczor, Ewa (2010): "Red and czerwony as cognitive categories: A corpus based study". SKASE Theoretical Linguistics 7/3: 19-52.

Goddard, Cliff (2004): "The ethnopragmatics and semantics of active metaphors". Pragmatics 36: $1211-1230$.

He, Guimei (2009): "English and Chinese cultural connotation of colour words in comparison". Asian Social Science 5/7: 160-163.

ISSN 1615-3014 
A Content Analysis of Colour-term Conceptual Metaphors in Modern Persian Poetry

Hupka, Ralph B./Zaleski, Zbigniew/Otto, Jurgen/Reidl, Lucy/Tarabrina, Nadia (1997): "The colours of anger, envy, fear, and jealousy: A cross-cultural study". Cross-Cultural Psychology 28/2: 156-171.

Itten, Johannes (1961): The art of colour. New York: Van Nostrand Reinhold.

Jacobs, Laurence (1991): "Cross-cultural colour comparisons: Global marketers beware!" International Marketing Review 8/3: 21-30.

Kiato, Kenji/Kiato, S. Kathleen (1986): "A study of colour association differences between Americans and Japanese". Human Communications Studies 13: 59-75.

Koller, Veronika (2008): "Not just a colour: Pink as a gender and sexuality marker in visual communication". Visual Communication 7/4: 395-423.

Lakoff, George (1993): "The contemporary theory of metaphor". In: Ortony, Andrew (ed.) ( ${ }^{2}$ 1993): Metaphor and Thought. Cambridge: Cambridge University Press. 202-251.

Lakoff, George/Johnson, Mark (1980a): "Conceptual metaphor in everyday language". Philosophy 77/8: 453-486.

Lakoff, George/Johnson, Mark (1980b): Metaphors We Live by. Chicago: University of Chicago Press.

Lakoff, George/Johnson, Mark (1999): Philosophy in the Flesh. New York: Basic Books.

Lakoff, George/Turner, Mark (1989): More than Cool Reason: A Field Guide to Poetic Metaphor. Chicago: University of Chicago Press.

Lan, Li/MacGregor, Lucy (2009): "Colour metaphors in business discourse". In: Bhatia, Vijay K./Cheng, Winnie/Du-Babcock, Bertha/Lung, Jane (ed.) (2009): Language for professional communication: Research, practice and training. Hong Kong: The Hong Kong Polytechnic University.

Leonard, S. David/Hill, G. William/Karnes, Edward W. (1989): "Risk perception and use of warnings". Proceedings of the Human Factors Society 33 ${ }^{\text {rd }}$ Annual Meeting: 550-554.

Leonard, S. David/Karnes, Edward, W./Schneider, T. (1988): "Scale values for warning symbols and words". In: Aghazadeh, Fereydoun (ed.) (1998): Trends in ergonomics/human factors $V$. Amsterdam: Elsevier.

Phillip, Gill (2006): Connotative meaning in English and Italian colour-word metaphor. http://metaphoric.de/10/Philip.pdf, accessed May 14, 2014.

Phillip, Gill (2011): Colouring Meaning: Collocation and connotation in figurative language. Amsterdam: John Benjamins.

Reddy, Michael J. (1979): "The conduit metaphor: A case of frame conflict in our language about language". In: Ortony, Andrew (1979): Metaphor and Thought. Cambridge: Cambridge University Press.

Sable, Paul/Okan, Akcay (2010): "Colour: Cross cultural marketing perspectives as to what governs our response to it". Proceedings of ASBBS Annual Conference 17/1: 950-954.

Sepehri, Sohrab (2005): The Secret of Red Flower. Tehran: Negah Publication Institute.

Sepehri, Sohrab (2007): The Water's Footfall. Tehran: Zanabkadeh Publications.

Sepehri, Sohrab (2008): The Traveler and We Nothing but Look. Tehran: Zanabkadeh Publications.

Siefring, Judith ( $\left.{ }^{2} 2005\right)$ : The Oxford dictionary of idioms. New York: Oxford University Press. Speake, Jennifer/Simpson, John ( $\left.{ }^{5} 2008\right)$ : The Oxford dictionary of proverbs. Oxford: Oxford University Press. 
Smith-Jackson, Tonya L./Wogalter, Michael S. (2000): "User's hazard perceptions of warning components: An examination of colours and symbols". Proceedings of the $14^{\text {th }}$ Triennial congress of the International Ergonomics Association and $44^{\text {th }}$ Annual Meeting of the Human Factors and Ergonomics Society 5: 150-153.

Tewksbury, Richard (2009): "Qualitative versus quantitative methods: Understanding why qualitative methods are superior for criminology and criminal Justice". Theoretical and Philosophical Criminology 1/1: 38-58.

Wogalter, Michael S. (1997): "Connoted hazard of Spanish and English warning signal words, colours, and symbols by native Spanish language users". Proceedings of the $13^{\text {th }}$ Triennial Congress of the International Ergonomics Association, IEA 97/3: 353-355.

Yu, Ning (2003): "Synesthetic metaphor: A cognitive perspective". Literary Semantics 32: 1934.

\section{Appendix: The collection of Persian poems containing colour terms (The Translated Version)}

1. He, God of plain, pours his voice to the green cup of silence.

2. thou amidst the green astronomical talks! ${ }^{\circledR}$

3. The wall collapsed onto the green garden gates.

4. I think about the tall blue, and the green low-fuss.

5. I know the wet fate of water, the green habit of tress. ${ }^{\circledR}$

6. The wind was blowing from the direction of the green basket of generosity. ${ }^{\circledR}$

7. Garden, full of green oozes, his inside greener, richer.

8. green garden of affinity! Up to what part of the desert ... The pure face of a deep slumber! ${ }^{\circledR}$

9. Our garden was perhaps an arc from the green circle of bliss. ${ }^{\circledR}$

10. We wear away our bodies to the canes, and we swing the smooth cradle to their green lullaby.

11. Between the tree and the green second ... the repetition of azure (blueness) ... mingles with the pining for words. ${ }^{\circledR}$

12. After long moments... A leaf grew on the grey tree of my window... And a green zephyr shook my sleeping fabric.

13. Behind us the green window of the poplar is closed.

14. Black ooze of his look combined with the green whisper of grasses.

15. Green singing dehisces: A woman's look as a sweet dream arrives at my eyes.

16. He draws a picture, a green picture: twigs, leaves.

17. Its eyes are the negation of the green calendar of life. ${ }^{\circledR}$

18. What happened that the starlings harvested your green slumber? ${ }^{\circledR}$ 
A Content Analysis of Colour-term Conceptual Metaphors in Modern Persian Poetry

19. Amidst the clovers, the presence of a greenfinch... ${ }^{\circledR}$

20. Go to horses and cows, and put the green grass of love before them. ${ }^{\circledR}$

21. I called you at the green night of networks, at the dawn of the river, at the sun of the marbles.

22. You handed me the green stalk of a message. ${ }^{\circledR}$

23. The white streak of green grass marble whispered.

24. And one night she pronounced the green message of love so clearly... ${ }^{\circledR}$

25. The green Fortune of Life mingled with the cool mountain air. ${ }^{\circledR}$

26. Like a slumber full of green stammer of an orchard. ${ }^{\circledR}$

27. How green I am today! And how alert my body! ${ }^{\circledR}$

28. The old "I" died out on these earthen green networks.

29. You are jumping from the green eye of a marsh ... Or you are washing wings by the perception fountain.

30. Before you reach the tree, there is an orchard aisle greener than God's dream. ${ }^{\circledR}$

31. Let's fetch baskets ... And fill them with all these reds and greens. (

32. And in which spring ... You will linger ... And the spirit level is full of green leaves?

33. And under the shade of that great green "Banyan" ... I well recall ${ }^{\circledR}$

34. And like the word "purity", it was grazing the green silence of the meadow. ${ }^{\circledR}$

35. And a green zephyr shook out my sleeping fabric.

36. And a cool breeze wafts away my sleep from the green hem of the blanket. ${ }^{\circledR}$

37. Water came, water came, and it brought black clays from Gods' plain.

38. The other side, my blackness is clear.

39. My childhood plays decayed on these black rocks.

40. Go up, go up ... Break the cord look, Break the black delusion.

41. Hurry; break the doors, split the delusion, the core of this black load is me.

42. I'm close to a night, my blackness is clear.

43. Come so I may not fear the towns whose black earth is pasture to cranes. ${ }^{\circledR}$

44. Someone came from the door silently, he kindled fire in blackness.

45. Black ooze of his look combined with the green whisper of grasses.

46. The drunken hell axe! Tell her: I drank the black zephyr of your eyes.

47. Black soil in the dream

48. A line from light is on the blackness: It seems the white gold shines on the ebony.

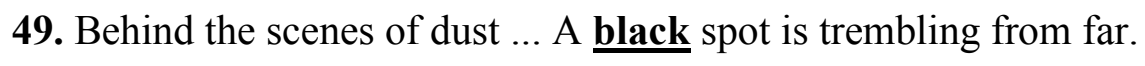


50. A shining tree swallowed my body in its black roots.

51. Amidst these black always... Speak, charming sister of perfection! ${ }^{\circledR}$

52. Bituminous ( $\underline{\text { black}) ~ w a l l ! ~ R i s e . ~}$

53. A first black fig in the acrid mouth of summer. ${ }^{\circledR}$

54. The blackest snakes dance.

55. It was black and a star ... (It was) an existence and a whisper.

56. The blackness and a thorn in the eyes do not see happening.

57. The blackness went, we reach the blue sky, and we meet the sky.

58. "Shasousa" were grown on a black marble: "Shasousa", my darkness alike!

59. "Shasousa", the nude and black blowing!

60. You illuminate the root scream in the space blackness, you ambush on the bloom fever, the scary gardener!

61. The pines too tall. The ravens too black. The sky blue enough. ${ }^{\circledR}$

62. You said: the essence of burning dance ... Was trickled in the throat of the black snake.

63. Yet my feet are in the black night (in the pitch of the night).

64. The black snake of the flower stem ... Was alive in the soft dance.

65. The black chicken come from far away ... Sat on the high roof of the night failure... Motionless like stone.

66. A black chicken come from far away ... Sings from the high roof of the night failure.

67. We went, and how tall the trees, and how black the viewing!

68. My look stuck to the black fabric of the flower stem ... And he felt the warmth of her veins: ...

69. And all the surface of journey was dull and black by the waves of industry. ${ }^{\circledR}$

70. And pass from my existence border ... The mute and cold black!

71. And each moment, you look at a black snake, the impatient eclectic!

72. Man had fun with his azure philosophies in the delicate laziness of a pasture. ${ }^{\circledR}$

73. The tall blue decorates our privacy.

74. I think about the tall blue and the green low-fuss.

75. The sky, bluer. The water, bluer. ${ }^{\circledR}$

76. The sky is not blue. It was blue during the day. ${ }^{\circledR}$

77. The sky is not blue. It was blue during the day. ${ }^{\circledR}$

78. No doubt, blue is blue there. ${ }^{\circledR}$

79. When my father died, the sky shone blue. ${ }^{\circledR}$ 
A Content Analysis of Colour-term Conceptual Metaphors in Modern Persian Poetry

80. Pulses became ashes. The blue coatings do not dance.

81. His larynx was filled with the blue characters of the rivers.

82. I was asleep, I saw a dream: the blue shining in the dream, the trembling of a leaf in the water.

83. Prostitutes (in the blue sky of the city) were looking at the bright furrows of jet planes. (B)

84. The blackness went, we reach the blue sky, and we meet the sky

85. The pines too tall. The ravens too black. The sky blue enough. ${ }^{\circledR}$

86. Neither will I lose heart to the blues (nor to the mermaids,) ${ }^{\circledR}$

87. Wow "me", what did your kid want from the above blue (indigo) dish at rocks night?

88. Where love is as blue as the wings of honesty. ${ }^{\circledR}$

89. And the moon landed from the eastern blue (indigo) stairs.

90. Let's not ask why the heart of truth is blue. ${ }^{\circledR}$

91. Yet, o honor of the blankness (whiteness) of paper! ${ }^{\circledR}$

92. You pick white flowers with fear and fascination in the turquoise pond.

93. One should be and follow the track of narration to the blank (white) text. ${ }^{\circledR}$

94. A line from light is on the blackness: It seems the white gold shines on the ebon.

95. Fly my minutes in the white sky of instinct. ${ }^{\circledR}$

96. In the crepuscule sky ... A white cloud passage

97. I drank in the white cup of the deserts moment by moment.

98. In the distance ... A swan suddenly woke up ... Washing Nile dust from its white wings.

99. The wall of shadows was destroyed. The hand of view in the distant horizon ... A lofty palace built of white marble.

100. The white streak of green grass marble whispered.

101. The deception whites are singing praise on the shadowless pillars.

102. It hurriedly blazes in the white December.

103. And the glory of butterflies of transmitting senses will whiten the highways of Air. ${ }^{\circledR}$

104. Its face is blank ( $\underline{\text { white }}$ ) like a chunk of summer holiday. ${ }^{\circledR}$

105. The brook edges ... Filled with the whispering wave in the white bed.

106. The stork was at the pond, like a white incident. ${ }^{\circledR}$

107. And the horse, remember? It was white. ${ }^{\circledR}$

108. And of the echo of the red rose beyond the hedge of harsh words. ${ }^{\circledR}$

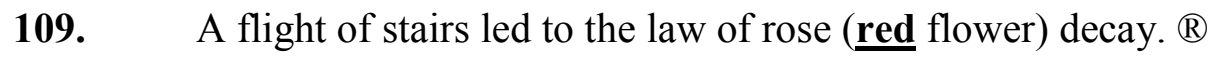


110. The red sunset poured over the rocks.

111. The red coronation in the water. ${ }^{\circledR}$

112. Our mission is not to fathom the secret of the rose (red flower). Our mission is perhaps to float in the beauty of the rose (red flower). ${ }^{\circledR}$

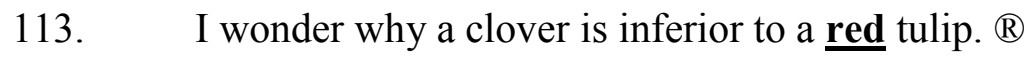

114. Death sings in the larynx of the robin (red throat). ${ }^{\circledR}$

115. I'm a Muslim: A ( $\underline{\text { red })}$ rose is my Qiblah. ${ }^{\circledR}$

116. Let's fetch baskets ... And fill them with all these $\underline{\text { reds }}$ and greens. ${ }^{\circledR}$

117. And call out, "O you whose baskets are full of dreams!" I have brought you an apple, the red apple of the sun. ${ }^{\circledR}$

118. There are three (dark) violet empty holes on his astonishing jelled face from the irradiation of time.

119. A cold corpse has remained in the (dark) violet privacy of my room for a long time.

120. The wound of night became (dark) violet in the desert that I was.

121. Two (dark) violet dished remained under his forehead.

122. The fascinating bitter plant! The violet hemlock of sun...

123. Remained in the plain ... A (dark) violet harvest.

124. When his eyes fell on the first violet curtain of the half day... It became dust from fear ... And I became all alone.

125. Our loneliness continued to the golden plain.

126. The morning came in an earth, brought golden apple from the golden garden.

127. The golden chain of the games and the bright valve of the stories went under the rubble.

128. A star fell in the golden dream of fishes. The perfume string broke. The water was replete with the magic shadow.

129. In this darkness... I open the gate to ancient grass. To the golden colours which we saw on the walls of myths. ${ }^{\circledR}$

130. And one should blow to wipe the dust off the golden face of death. ${ }^{\circledR}$

131. A leaf fell from the grey tree of my window, ...

132. After long moments... A leaf grew on the grey tree of my window... And a green zephyr shook my sleeping fabric.

133. I plant his grey eye with my own look.

134. The dark patterns stimulated ... and in the colour of grey ... the designs poured from the devil. 
Mohammad Aliakbari, Mohammad Bagher Shabani and Fereshteh Khosravian:

A Content Analysis of Colour-term Conceptual Metaphors in Modern Persian Poetry

135. In the morning, mother would take a basket of water for yellow flowers. ${ }^{\circledR}$

136. To whose foot of repose did the canary tie the yellow string of its song? ${ }^{\circledR}$

137. The orange plant of sun ... is growing in the marsh of my room gradually. 